\title{
RETORNOS À ESCALA E MERCADO COMPETITIVO: TEORIA E EVIDÊNCIAS EMPÍRICAS ${ }^{1}$
}

Resumo - Em nível elementar, mas rigoroso, desenvolve-se o conceito de retornos à escala. Argumenta-se que retornos crescentes ou constantes não são compatíveis com a existência de mercados competitivos, pois se convergiria para um número pequeno de empresas, o que contradiz o mundo observado. A tese é que a curva de custo médio tenha forma de U. À direita do mínimo, prevalecem retornos crescentes, no mínimo retornos constantes, e à direita, retornos decrescentes. Em regime de competição, livre de imperfeições de mercado, a firma converge para o ramo de retorno crescente. Quando, no mundo real, se detecta retorno crescente ou constante, tem-se um sinal claro que as firmas estão enfrentando restrições devidas a imperfeições de mercado, as quais as impedem de mover para o ramo de retornos decrescentes da curva de custo médio. Por isto, os resultados de modelos econométricos que detectam retornos crescentes ou constantes devem levar o estudioso a indagar quais imperfeições de mercado fundamentam esses retornos. Além disso, o conhecimento das imperfeições de mercado é básico à formulação de políticas econômicas que visem ao desenvolvimento econômico, num contexto de oportunidades iguais para todo. Os dados disponíveis cobriram seis culturas e mostraram um padrão de muitos produzindo muito pouco, e de poucos produzindo muito, padrão mais visível nas culturas modernas, como a soja. Os resultados revistos de um modelo econométrico indicaram que o grupo mal sucedido, de dois grupos de pequenos produtores, tem retornos crescentes à escala e não pode expandir a produção, dadas as restrições.

Palavras-Chaves: Retornos à escala, estrutura de mercado, grãos.

${ }^{1}$ Recebido em 30/07/2004. Aceito em 20/09/2004.

${ }^{2}$ Eliseu Alves é pesquisador da Embrapa. As sugestões de Wilson da Cruz Vieira, da Universidade Federal de Viçosa, foram muito valiosas. 


\section{Introdução}

Este artigo discute o tema retorno à escala, do ponto de vista de implicações para a existência de mercado competitivo, do tamanho das firmas e de discriminações contra o pequeno empreendimento. Aportam-se evidências empíricas e defende-se a tese de que a curva de custo médio tenha a forma de $\mathbf{U}$, desde que se permita a expansão da produção, sem restrições.

\section{Digressão técnica}

Um mínimo de teoria da produção faz-se necessário para expor o tema. A tecnologia é descrita por uma função de produção do tipo $y=f\left(x_{1}, x_{2}, \ldots, x_{n}\right)$. O produto é y e x's são os insumos. A função de produção satisfaz a determinadas propriedades matemáticas que não serão discutidas. ${ }^{3}$ Se a produção comportar mais de um produto, recorre-se ao conjunto de produção.

A outra face da função de produção é a função custo. Num mercado em que cada produtor não influencia o preço e num mundo sem incerteza, é possível derivar a função custo da função de produção, ela é dada por $\mathrm{C}(\mathrm{w}, \mathrm{y})$; w é o vetor preço dos insumos; y, o nível de produção; e $\mathrm{C}(\mathrm{w}, \mathrm{y})$, custo total. Conhecida a função custo, pode-se retornar a função de produção. Por isto, diz-se que essas duas funções são duais. Para uma discussão detalhada, veja Alves, 1996, e Chambers, 1994.

Note-se que a função custo não oferece dificuldade para o desenvolvimento da teoria que engloba a produção múltipla e é mais amena aos modelos econométricos. Sintetiza ainda a decisão dos agricultores, como

\footnotetext{
${ }^{3}$ As principais propriedades são:

(i) $f(x) \geq 0$; (ii) $f(0)=0$; (iii) $x \geq z \rightarrow f(x) \geq f(z)$ e $\mathrm{F}(\mathrm{x})$ é semi-contínua superior, (Alves, 1995 p.7).
} 
minimizadores do dispêndio, sobre alcançar determinada produção. Portanto, representa os dados observados que se presume que foram gerados por produtores que procuram obter o máximo dos recursos que comandam. A função de produção não satisfaz a esta condição.

A função custo satisfaz às seguintes propriedades gerais:

a) $C(w, 0)=0 ; C(w, y)>0$ para $y>0$; b) é linear homogênea em $\mathrm{w}$, preços dos insumos; c) é côncava em w ; d) é monótona crescente em w ou y, não necessariamente estritamente crescente; e) cresce sem limites com y; f) é semi-contínua inferior em y (Alves, 1995 p. 9-13).

Num mercado competitivo, sobrevivem os mais eficientes. Estes estão procurando obter o máximo dos recursos que comandam, ou seja, como aproximação, estão maximizando a renda líquida. Note-se o comportamento maximizador é ditado pelo mercado competitivo. Em mercados não competitivos imperfeitos, este comportamento não necessita estar presente.

A questão técnica que se propõe é a existência do máximo. A renda líquida máxima pode crescer sem limites. Por isto, é preciso examinar as condições de existência do máximo. Em geral, admite-se que o produtor possa alugar os recursos compatíveis com o máximo, ou seja, não está sujeito a restrições. É possível introduzir no modelo as restrições, inclusive o risco. Nesse caso, a renda líquida máxima será menor. Se as restrições forem uniformes entre os produtores, a distribuição dos índices de eficiência econômica não será afetada.

A renda líquida é dada por $R(y, w, p)=\operatorname{Max}_{y}\left\{p^{*} y-C(w, y)\right\}$, em que p é o preço do produto y, e w, vetor de insumos. Se C(w,y) admitir derivada em relação a y, num mundo sem restrições e incerteza, obterse-á a celebrada igualdade entre o preço, p, e o custo marginal: $\partial C(w, \hat{y}) / \partial y=C^{\prime}(w, \hat{y})=p$, sendo a derivada em relação a y, quan- 
do p e w são dados e conhecidos, e $y$, o nível ótimo de produção. No gráfico abaixo, o máximo para o preço, $\mathbf{q}$, corresponde à produção, $\mathbf{d}$. Note-se que custo médio é menor que q. Assim, a renda líquida é positiva, e há incentivo à entrada de novos produtores.

Caso seja positiva a renda líquida, haverá incentivos para entrada de novos produtores, e o preço cairá para p. A renda líquida máxima ocorrerá em $\mathbf{x}^{4}$. Observe-se, no gráfico, que, então, o custo marginal será igual ao custo médio: $C(w, x) / x=C^{\prime}(w, x)=p$. Portanto, a receita bruta correspondente à renda líquida máxima, será igual ao custo, $p^{*} x=C(w, x)$. Assim, em $\mathbf{x}$, a renda líquida será nula, e não haverá incentivos para entrada de produtores novos, ou de ampliação da produção, ou seja, a renda bruta somente remunerará o custo dos insumos.

\section{Retornos à escala}

Vejamos algumas importantes restrições.

a) Retorno constante à escala: se os insumos forem dobrados, a produção dobrará; ou, se $t>0, t^{*} y=f\left(t^{*} x\right)=t^{*} f(x)$, em que x é o vetor de insumos. Importante: Se a tecnologia comportar retorno constante à escala, a produção será zero, no caso de ocorrer renda líquida negativa, e $x=0$, porque será melhor não produzir nada. Ora, se a renda líquida for positiva para algum $\mathrm{x}$, ela poderá crescer indefinidamente se os insumos forem multiplicados por números positivos crescentes. Como a curva do custo médio é uma reta paralela ao eixo da quantidade e igual ao custo marginal, ele será o mesmo para qualquer dimensão; por isto, os estabelecimentos de menores tamanhos serão tão eficientes quantos os grandes ${ }^{5}$. No mundo real, há

\footnotetext{
${ }^{4}$ A renda líquida máxima ocorre no ponto em que linha de preço corta a curva do curto marginal, no seu ramo crescente. A curva do custo marginal corta a curva do custo médio no seu ponto mínimo, quando ele existe.

${ }^{5}$ Note-se que, se o preço do produto for menor que o custo médio, a produção será nula; se for maior ou igual, a produção poderá ser qualquer valor, portanto, indefinida, e poderá expandir-se sem limites.
} 
uma miríade de tamanhos, e isto será compatível com retornos constantes, em todo o campo de definição da função de produção, somente se houver barreiras não-simétricas ao crescimento das firmas. Aí, os diferentes tamanhos serão ditados pelas diferentes barreiras. Mas é possível encontrar retornos constantes num campo de definição mais restrito, como é documentado por alguns estudos (Alves, Souza e Brandão, 2001).

b) Retornos crescentes: se os insumos forem dobrados, a produção mais que dobrará. Então, a curva do custo médio decrescerá com o tamanho, e os estabelecimentos maiores serão mais eficientes. Esse modelo de função de produção é compatível com crescimento contínuo e ilimitado dos estabelecimentos, até que tudo convirja para um único estabelecimento. Por isto, a hipótese de retornos crescentes é irreal, exceto para um ramo da função. Note-se que, na presença de retornos crescentes, as firmas têm incentivos para quebrar as barreiras de mercado, e as que o conseguirem irão se expandir ilimitadamente.

c) Retorno decrescente: Se os insumos forem dobrados, a produção menos que dobrará. Este modelo de produção é compatível com a idéia de tamanho ótimo, que é dependente do nível de preços. As firmas que correspondam ao tamanho ótimo são, economicamente, as mais eficientes ${ }^{6}$. Num ambiente de mercado competitivo, as firmas convergirão para esse ótimo. $\mathrm{O}$ modelo de retornos decrescentes encontra grande aceitação, pois se admite que, se a escala de produção começar a se expandir, chegará a um ponto em que algum fator não poderá mais ser aumentado. Neste momento, o retorno decrescente mostrará sua face.

d) Três estágios simultâneos. É costume postular a presença de três estágios na mesma função de produção, em vez de um único. A presença dos três estágios corresponde à curva de custo médio (Cme) em forma de $\mathbf{U}$, do gráfico, com a presença de um ponto, $\mathrm{x}$, de custo mínimo. Num mercado competitivo, o preço do produto converge para

\footnotetext{
${ }^{6}$ Retornos decrescentes são compatíveis com vários tamanhos. Cada firma tem o ótimo compatível com sua expec-
} tativa. 
o mínimo ${ }^{7}$. Assim, p corresponde ao preço, abaixo do qual a produção é inviável, denominado de preço de sobrevivência. A curva, Cma, representa o custo marginal e descreve a oferta da firma a partir do ponto que intercepta $\mathrm{Cme}$. À esquerda de $\mathrm{x}$, há retorno crescente à escala; em x, o retorno é constante; e à direita de $\mathrm{x}$, é decrescente.

É conhecido que, sob a hipótese de maximização da renda líquida, o ótimo ocorrerá no estágio de retorno decrescente. Se o preço do produto igualar-se ao custo mínimo, o ótimo se verificará no limiar do retorno decrescente. Para preços maiores, o máximo estará no estágio de retorno decrescente.

Imaginando-se que um estabelecimento esteja iniciando a produção; dispõe-se da terra e de alguns investimentos; e a decisão é crescer cautelosamente. Na curva de abaixo do gráfico, a localização é à esquerda de x; como o retorno é crescente, a renda líquida não será maximizada. Portanto, o estabelecimento não será eficiente, e os recursos fixos, inclusive o trabalho da família, estarão sub-remunerados.

Como há possibilidade de aumentar a renda líquida, à medida que o empreendedor conseguir superar as restrições externas de crédito, impostas pelo mercado, e as internas inerentes ao empreendedor, em razão de uma avaliação excessivamente conservadora do risco e falta de conhecimentos, ele aumentará a produção e convergirá para o ótimo, que ficará ou em x ou à sua direita. Mas, ressalte-se que são as restrições que impedem o produtor de caminhar para ótimo.

O gráfico pressupõe que, tecnologicamente, a curva de custo médio represente a tecnologia mais eficiente, ou seja, não há nenhuma outra curva de custo médio abaixo dela. Pode ocorrer que dado produtor não tenha acesso à tecnologia mais eficiente, em virtude de falta de conhecimento e de recursos para realizar os investimentos necessários.

\footnotetext{
${ }^{7} \mathrm{O}$ mínimo não precisa ser único. Pode haver um segmento, paralelo ao eixo de quantidade, antecedido pelo ramo decrescente e sucedido pelo ramo crescente.
} 
Nesse caso, ele não receberá a renda líquida máxima, por não ter adotado a tecnologia mais eficiente, embora, em relação à tecnologia em curso ele possa estar otimizado.

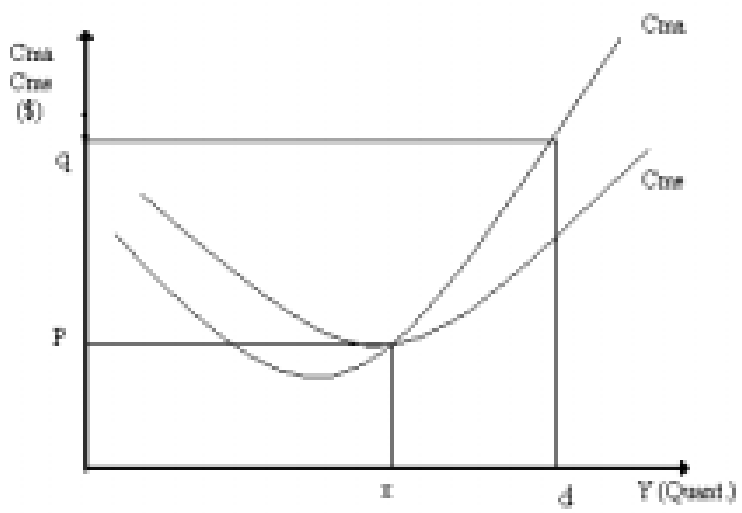

\section{Tamanho do negócio}

A caracterização dos tipos de retornos ajuda a compreender o problema do agricultor. Mas, na prática, é complicado determinar a estrutura de produção. Se houver dados, um caminho será estimar a função de produção ou a função custo; na realidade, quase sempre se estima um ramo. ${ }^{8}$ Se o retorno for crescente ou constante, a escala de produção do estabelecimento estará aquém do ót imo, ou seja, a produção poderá ser expandida até o ramo dos retornos decrescentes. Deve-se suspeitar de restrições externas, como as de crédito, como responsáveis pela produção estar aquém do ótimo. As restrições podem relacionar-se com o capital humano do produtor, aí, deve-se analisar o grau de instrução, quanto cosmopolita ele é e qual sua inclinação ao risco. Há, ainda, outras restrições importantes, como as que seguem.

\footnotetext{
${ }^{8}$ Técnicas de programação matemática também podem ser usadas. Outra possibilidade, é estimar a função custo que exige variação dos preços dos insumos e das quantidades produzidas e se coaduna com os dados coletados.
} 


\section{a) Indivisibilidade dos insumos}

O modelo tem algumas pressuposições escondidas, e a mais restritiva delas é que cada insumo é divisível. Ora, trabalho, máquinas e equipamentos não são divisíveis, mas, se mercado de leasing, aluguel e de trabalho estiver funcionando bem, o problema da indivisibilidade será, em larga medida, solucionado. No caso, é possível alugar terras, máquinas, equipamento e contratar horas de trabalho, de acordo com o plano ótimo de produção. Assim, as imperfeições dos mercados levam à apropriação exagerada de terra, o tamanho da exploração fica também condicionado ao ótimo uso das máquinas e equipamentos adquiridos e à indivisibilidade do trabalho. Digamos que o uso ótimo de uma colheitadeira corresponda a 700 hectares; quem cultivar área menor não usará eficientemente sua máquina. Se dois homens cuidam de mil bois, o pecuarista de corte que tem dois empregados permanentes somente terá eficiência máxima se explorar esse número de cabeças. Contudo, as indivisibilidades perdem poder de explicar o crescimento da área média do estabelecimento e do tamanho do negócio, quando os mercados funcionam bem.

\section{b) Mercado imperfeito de terra e crédito subsidiado}

Na presença de retornos crescentes ou constantes à escala, a tendência é que a área média dos estabelecimentos aumente, e tudo, no extremo, convergiria para um único estabelecimento. Como a área média dos estabelecimentos tem crescido, pode-se, incorretamente, afirmar que o nosso mundo é de retornos crescentes ou constantes. Teoricamente, eles são incompatíveis com a existência de mercados competitivos.

Nos Estados Unidos, pesquisas empíricas não confirmam a presença de retornos constantes ou crescentes, mas é sabido que os subsídios são, em nível de produtor, apropriados, principalmente pela terra. Assim, eles incentivam a apropriação de terra. Como os produtores maiores recebem mais do governo, eles têm incentivos para adquirir ou alugar mais terra, e o crescimento da área média dos estabelecimentos é impulsiona- 
do. O mesmo efeito tem o crédito subsidiado. Portanto, são os subsídios que têm maior poder de explicar o crescimento da área média dos estabelecimentos americanos, e não os retornos crescentes à escala, visto que lá as imperfeições de mercado têm menor importância. O subsídio ao crédito tem, entre nós, efeito análogo.

\section{c) Tecnologias que aumentam a produção}

A tecnologia faz a oferta crescer a taxas mais elevadas que a demanda. Os preços dos produtos podem cair, mas isto não permanece indefinidamente. Em primeiro lugar, a reação é reorganizar o estabelecimento para manter uma remuneração do empreendedor competitiva com alternativas, mas há limites nessa reorganização. Em segundo lugar, ultrapassado o limite, o empreendedor vende ou aluga o estabelecimento, em busca de melhor remuneração. Não por serem menos eficientes, mais pelo fato de a área não gerar renda competitiva, os pequenos agricultores são os que, mais freqüentemente, vendem suas propriedades e migram. Deste modo, cresce á área média do estabelecimento, como conseqüência das tecnologias que aumentam a produção e de outras políticas que tenham o mesmo efeito, quando a demanda não cresce proporcionalmente.

\section{d) Mercado imperfeito de produtos e fatores}

É comum ter o preço de insumos e produtos conectados aos volumes de compra e venda; os pequenos produtores pagam mais pelos insumos e recebem menos pelos produtos, ou seja, estamos na presença de imperfeições dos mercados de insumos e produtos. Essa imperfeição pode levar os pequenos produtores a venderem seus estabelecimentos, e o tamanho do negócio crescerá, ou ainda, menos drasticamente, elas causam uma exploração menos intensiva, e recursos são deixados ociosos, o que reflete na área que cada exploração ocupa. 


\section{e) Direito de herança}

Há, ainda, os fatores institucionais que freiam o crescimento da área dos estabelecimentos e podem levar a um fracionamento excessivo. $\mathrm{O}$ mais importante deles é o direito de herança. Os minifúndios nascem, em larga medida, do direito de herança. É claro que fatores que restringem a mobilidade dos agricultores, como o baixo grau de instrução e a falta de oportunidades de emprego em outros setores da economia, compõem o efeito negativo do direito de herança na área média dos estabelecimentos.

\section{f) Fatores históricos}

O tamanho do estabelecimento é também dependente de fatores históricos. As capitanias hereditárias tiveram influência na geração de latifúndios, num passado mais remoto; a inflação persistente do período 1950$90 \mathrm{fez}$ da terra uma reserva de valor; e o crédito subsidiado da década de 70 permitiu, em conjunção com a idéia de reserva de valor, o acúmulo de muita terra nas mãos de poucos.

Assim, os fatores históricos, institucionais e ligados às imperfeições de mercado podem confundir a percepção da função de produção, levando a crer que se está na presença de uma função de produção coerente com retornos crescentes ou constantes à escala, em todo o seu campo de definição. Econometricamente, não é fácil desenvolver modelos para estimar a função de produção que livre os dados observados dessas influências. Se não tomar cuidado, portanto, pode-se, falsamente, concluir pela existência de retornos crescentes ou constantes.

\section{Volume de produção e eficiência econômica}

Se não houver obstáculos que impeçam que as firmas movam para a escala ótima de produção, elas devem convergir para índices de eficiência iguais. A distribuição dos índices observados deve estar muito con- 
centrada em torno de um valor comum. Não deve haver correlação entre o volume de produção e eficiência. Na prática, isto pode não ocorrer, pelas seguintes razões, todas elas ligadas às imperfeições de mercado:

a) O acesso à assistência técnica de qualidade, hoje principalmente particular, depende de recursos para pagar os serviços de assistência técnica. Quem produz em maior volume tem os recursos necessários, razão por que pode adotar tecnologias mais eficientes e executálas corretamente.

b) Outro elemento indispensável à maior rentabilidade do negócio é o crédito. A maior produção sofre muito menos restrições bancárias, portanto, o racionamento externo do crédito é muito menos severo; por isto, ela é financiada a taxa de juros menores e desfruta de montantes de recursos e prazos mais dilatados. Assim, a maior produção tem muito mais facilidade para evoluir para escala ótima.

c) Os produtores maiores compram os insumos a preços menores e recebem mais pela produção. Eles têm mais acesso à informação, aos grandes mercados, inclusive o externo, razão pela qual enfrentam um mundo muito menos incerto e têm melhores condições para programar o negócio.

d) Um grau de instrução mais elevado facilita a mobilidade, em termos de viagens no Brasil e exterior, e ainda o acesso a técnicos e homens de negócios mais bem preparados. A troca de experiência gera externalidades importantes para a maximização dos lucros.

Qual lição da análise acima? Simples. Se for encontrada forte relação entre volume de negócio e eficiência, não se deve acreditar que os grandes negócios sejam intrinsecamente mais eficientes. Mas, deve-se pesquisar de que vantagens, ligadas às imperfeições de mercado, eles desfrutam, em oposição à produção menor. É natural um amplo espectro de variação no que respeita ao volume de negócio dos estabelecimentos, pois as tecnologias, os recursos que comandam e os objetivos dos produtores são diferentes. O que leva à suspeita de discriminação é uma correlação positiva entre volume e eficiência. 


\section{O limite superior e inferior do volume de produção}

Há limites para que o volume de negócio não afete a rentabilidade. Empiricamente, as megas fazendas têm fracassado, em virtude de complicações de supervisão e falta de flexibilidade, mas as técnicas modernas de administração e a eletrônica têm superado estas dificuldades.

Mas, e o limite inferior do volume de negócios? Fixadas a tecnologia e a combinação de produtos, há um tamanho mínimo que não proporciona à família uma renda suficiente para permanecer no meio rural. Quando isto ocorre, o estabelecimento é vendido? Nem sempre. A decisão de migrar tende a ser evitada. Há o apego à terra, em razão de segurança e de tradições. Em termos de tempo parcial, o agricultor, pelo trabalho fora do estabelecimento, pode completar a renda, ou então pode fazê-lo pela indústria caseira e pelo turismo rural. A aposentadoria e as doações também freiam a venda do negócio. A falta de oportunidades de emprego tem efeito semelhante, ou seja, os fatores arrolados tendem a enfraquecer a relação que existe entre o volume de negócio e a necessidade mínima de renda da família, mas eles não têm a capacidade de anular esta relação. Assim, o volume de negócio mínimo é fortemente correlacionado com padrão de vida que o agricultor e sua família desejam ter.

E o agricultor comercial? Ora ele é um empreendedor, e como tal é consciente do custo de oportunidade de seu tempo. Por isto, tende a calibrar o tamanho da produção com olhos na eficiência e na remuneração que obtém pelo risco que corre. Se renda líquida máxima não lhe proporciona uma remuneração competitiva em relação às alternativas, encerrará suas atividades no ramo que está.

\section{Fatores que explicam os retornos crescentes ou constantes}

Embora com alguma repetição, julgou-se importante sintetizar a discussão sobre os fatores que induzem à presença de retornos constantes ou crescentes, além das indivisibilidades. 
a) Mercados imperfeitos de arrendamento de terra, aluguel de máquinas e de equipamentos, de crédito, de insumos e produtos exacerbam o efeito das indivisibilidades, que afetam a capacidade das firmas de evoluírem para o ramo de retornos decrescentes da função de produção ou motivam a aquisição de terras, de máquinas e equipamentos. Se estes mercados funcionarem bem, o incentivo para aquisição é substituído pelo incentivo para o arrendamento e aluguel. Como se permitem opções adicionais de escolha, a renda líquida tenderá a crescer.

b) crédito inadequado impede a expansão do tamanho da firma, de modo que possa explorar adequadamente os recursos fixos. Quando este mercado funciona bem, o efeito ruim das indivisibilidades é minimizado. É claro que há fatores históricos que explicam o pendor para aquisição de terra, mas uma forma de reduzir seu impacto é aperfeiçoar o mercado de terras e o de aluguel, em geral.

c) empreendedor deixa de expandir a produção porque estima, incorretamente, os riscos de falência e falta-lhe conhecimento. O nível de escolaridade e a mobilidade têm a ver com a visão incorreta do risco, mas o acesso à informação e a capacidade de decodificação são cruciais para o avaliar corretamente. Os assentados da reforma agrária e a agricultura familiar não podem pagar pela extensão rural, por isto erram, mais frequientemente, na escolha de tecnologia e do tamanho ótimos.

\section{Evidências empíricas}

Há dois grupos de evidências empíricas. O primeiro documenta distribuição da produção por classes de volume produzido, enquanto o segundo relata diversidade de retornos à escala, entre dois grupos de pequenos produtores. 


\subsection{Volume da produção}

Os dados são do censo agropecuário de 1995/96 e foram preparados pelo IBGE. Referem-se ao volume de produção obtido, e não apenas àquela comercializada, e ao número de informantes. Assim, é possível que um grande estabelecimento, que produz pouco feijão, esteja contado na classe de miniprodução. O índice de Gini foi calculado para um número de classes bem maior que o sintetizado abaixo. $\mathrm{O}$ retrato mostrado não permite ver a evolução. Uma pálida idéia dela pode ser captada quando se comparam diferentes culturas ou diferentes safras da mesma cultura, como no caso do feijão. Quanto ao volume, há as classes de mini, pequeno, médio e grande.

Há dois grupos de produtos: a pequena produção é muito importante para os agricultores e para o abastecimento, a exemplos do feijão primeira safra e do leite; a pequena produção é importante para os agricultores e pouco importante para o abastecimento, a exemplo do arroz, milho, soja e café.

\section{Feijão primeira safra}

Cabem as seguintes observações:

a) Cerca de 1,8 milhão de informantes relataram a produção de 1,4 milhão de toneladas, e $98,2 \%$ dos informantes produziram 5 toneladas ou menos;

b) Os informantes, com exceção de cerca de $2 \%$, são miniprodutores e respondem por $64,6 \%$ da produção. Os mini e pequenos produtores responderam por $81,4 \%$ do volume produzido e equivaleram a $99,8 \%$ dos informantes. Assim, o feijão da primeira safra, pelo censo 1995/ 96, tem a produção dominada pelos mini e pequenos produtores, sem os quais o abastecimento teria sido inviável. 
c) A distribuição é muito concentrada nas classes de mini e pequenos informantes, com índice de Gini de 0,34.

No feijão da segunda safra, registrou-se um número de informantes de 342,5 mil, com produção de 1,4 milhão de toneladas. Os miniprodutores são $97,2 \%$ da população e contribuíram com 46,2\% do volume de produção. Os pequenos correspondem a $1,7 \%$ da população e produziram $8,4 \%$ da produção. Os dois grupos contribuíram com 54,6\% do volume colhido. Embora importantes, esses dois grupos têm importância relativa bem menor que no caso da primeira safra. Os grandes produtores, (mais de 40 toneladas por informante), 0,3\% da população, responderam por $33,5 \%$ da colheita. Assim, a distribuição foi menos concentrada nas classes de pequenos volumes de produção, e o índice de Gini equivaleu a 0,52 . Os grandes produtores têm ainda um papel importante no abastecimento.

Há também o feijão da terceira safra, mais tecnificado e menos relevante, quanto ao volume de produção. Registrou-se um número de 22,1 mil informantes e uma produção de 148,2 mil toneladas. Os mini e pequenos produtores foram pouco relevantes, quanto ao volume produzido. Mini: 90,5\% dos informantes, contribuição de 10,5\% da colheita. Pequenos: $3,1 \%$ da população e 3,2\% da produção. Grandes: $2,9 \%$ da população e $75,5 \%$ da colheita. Assim, os grandes produtores (mais de 40 toneladas) têm grande peso na produção, embora sejam ainda insignificantes quanto ao número. $\mathrm{O}$ índice de Gini equivaleu a 0,86 . 
Tabela 1 - Distribuição da produção de feijão, primeira safra, em classes de produtores e de produção. Censo Agropecuário 1995/96

\begin{tabular}{lcccc}
\hline $\begin{array}{c}\text { Classes de } \\
\text { produtores }\end{array}$ & $\begin{array}{c}\text { Classes de } \\
\text { produção (ton) }\end{array}$ & $\begin{array}{c}\text { Informantes } \\
\text { Número }\end{array}$ & $\%$ & $\begin{array}{c}\text { Produção } \\
\%\end{array}$ \\
\hline Mini & {$[0,5]$} & 1.741 .105 & 98,19 & 64,58 \\
Pequenos & $(5,10]$ & 20.357 & 1,15 & 9,65 \\
& $(10,20]$ & 7.512 & 0,42 & 7,14 \\
Médios & $(20,30]$ & 2.002 & 0,11 & 3,48 \\
& $(30,40]$ & 569 & 0,03 & 1,39 \\
Grandes & Mais de 40 & 1574 & 0,10 & 13,76 \\
Total & & 1.773 .119 & 100,00 & 100,00 \\
\hline
\end{tabular}

Fonte IBGE, solicitação da Embrapa. Produção informada = 1.451.877 ton. Gini = 0,34.

\section{Arroz}

A grande maioria é de mini e pequenos produtores, $95,8 \%$ da população de informantes, mas responderam por apenas $16,9 \%$ da colheita. Os grandes produtores, $1 \%$ do universo, produziram $72,4 \%$ da produção.

Tabela 2 - Distribuição da produção de arroz em classes de produtores e de produção. Censo Agropecuário 1995/96

\begin{tabular}{lcccc}
\hline $\begin{array}{c}\text { Classes de } \\
\text { produtores }\end{array}$ & $\begin{array}{c}\text { Classes de } \\
\text { produção (ton) }\end{array}$ & $\begin{array}{c}\text { Informantes } \\
\text { Número }\end{array}$ & $\%$ & $\begin{array}{c}\text { Produção } \\
\%\end{array}$ \\
\hline Mini & {$[0,5]$} & 847.955 & 91,41 & 13,28 \\
Pequenos & $(5,10]$ & 41.483 & 4,47 & 3,58 \\
& $(10,20]$ & 15.338 & 1,65 & 2,68 \\
Médios & $(20,50]$ & 8.880 & 0,96 & 3,61 \\
Grandes & $(50,100]$ & 4.775 & 0,51 & 4,42 \\
Total & Mais de 100 & 9187 & 1,00 & 72,43 \\
\hline
\end{tabular}

Fonte IBGE..Produção= 8.047.983 ton.. Gini = 0,84. 
Concluindo, a pequena colheita de arroz não foi muito relevante, quanto ao abastecimento, e, nesse caso, destacou-se a grande produção. Como os grandes produtores equivaleram a 9.187, não foi difícil contatá-los por e-mail.

\section{Milho}

Trata-se de lavoura disseminada em todo o Brasil, com 2,5 milhões de informantes e uma colheita, à época, de 25,5 milhões de toneladas. Os mini e pequenos informantes corresponderam a $97.7 \%$ da população e colheram 36,4\% da safra; os médios e grandes, a 2,3\% do universo de informantes e responderam por $63,6 \%$ da produção. Somente os grandes informantes (mais de 200 toneladas por informante), cerca de $16 \mathrm{mil}$, responderam por $47,6 \%$ da produção. Desse modo, o milho é dominado pela grade produção. Ao contrário do arroz, os mini e pequenos produtores ainda tiveram peso na produção, contudo, este foi bastante insignificante, quando comparado com o feijão da primeira safra.

Tabela 3 - Distribuição da produção de milho, em classes de produtores e de produção. Censo Agropecuário 1995/96

\begin{tabular}{lcccc}
\hline $\begin{array}{l}\text { Classes de } \\
\text { produtores }\end{array}$ & $\begin{array}{c}\text { Classes de } \\
\text { produção (ton) }\end{array}$ & $\begin{array}{c}\text { Informantes } \\
\text { Número }\end{array}$ & $\%$ & $\begin{array}{c}\text { Produção } \\
\%\end{array}$ \\
\hline Mini & {$[0,5]$} & 2.230 .512 & 87,82 & 16,13 \\
Pequenos & $(10,20]$ & 154.083 & 6,07 & 8,62 \\
& $(20,50]$ & 95.873 & 3,77 & 11,67 \\
Médios & $(50,100]$ & 28.654 & 1,13 & 7,90 \\
Grandes & $(100,200]$ & 14.776 & 0,58 & 8,13 \\
Total & Mais de 200 & 15994 & 0,63 & 47,55 \\
\hline
\end{tabular}

Fonte IBGE, solicitação da Embrapa. Produção informada=25.521.424 ton. Gini =0,79. 


\section{Café}

Cerca de 317,6 mil pessoas informaram que produziram 2,8 milhões de toneladas de café em coco, ou seja, 8,9 toneladas por informantes. Os mini informantes equivaleram a 74,6\% do universo de informantes e colheram apenas $10,1 \%$ da produção. Juntando-se os mini aos pequenos, o grupo equivaleu a $89,8 \%$ da população e respondeu por $25,0 \%$ da produção. Logo, os médios e os grandes equivaleram a 10,2\% do universo e colheram $75,0 \%$ da safra. Somente os grandes produtores, em número de 7.439 , colheram $49,7 \%$ da safra.

Os que produziram mais de 30 toneladas, 15.982 informantes, 5,0\% do universo, colheram cerca de $62,7 \%$ da safra. Na lavoura de café, os mini e pequenos produtores, bastante numerosos, tiveram relevância pouco significante no abastecimento do país e nas exportações.

Tabela 4 - Distribuição da produção de café em coco, em classes de produtores e de produção. Censo Agropecuário 1995/96

\begin{tabular}{lcccc}
\hline $\begin{array}{l}\text { Classes de } \\
\text { produtores }\end{array}$ & $\begin{array}{c}\text { Classes de } \\
\text { produção (ton) }\end{array}$ & $\begin{array}{c}\text { Informantes } \\
\text { Número }\end{array}$ & $\%$ & $\begin{array}{c}\text { Produção } \\
\%\end{array}$ \\
\hline Mini & {$[0,5]$} & 236.136 & 74,61 & 10,07 \\
Pequenos & $(5,10]$ & 33.794 & 10,64 & 8,56 \\
& $(10,15]$ & 14.622 & 4,60 & 6,39 \\
Médios & $(15,30]$ & 16.234 & 5,11 & 12,25 \\
Grandes & $(30,60]$ & 8.543 & 2,69 & 13,01 \\
Total & Mais de 60 & 7439 & 2,35 & 49,72 \\
\hline
\end{tabular}

Fonte IBGE, solicitação da Embrapa. Produção informada = 2.838.195 ton. Gini =0,79. 


\section{Soja}

As informações foram prestadas por 243 mil pessoas que produziram 21,6 milhões de toneladas. Os grandes produtores, mais de 200 toneladas, em número de $18.810,7,7 \%$ do universo, colheram $72,0 \%$ da safra, e os que produziram mais de 100 toneladas, $13,6 \%$ da população de informantes, foram responsáveis por $81,4 \%$ da safra.

Os miniprodutores, $42,8 \%$ do universo de informantes, compareceram com $1,8 \%$ da produção. Juntando-se os mini com os pequenos, cobre-se $76,9 \%$ do universo de informantes e apenas $11,2 \%$ da produção.

Salienta-se que os mini e pequenos produtores tiveram expressão numérica muito forte na lavoura de soja e pouca relevância na produção. Assim, a lavoura de soja é muito importante para os mini e pequenos produtores, apesar de eles não serem relevantes para a produção.

Tabela 5 - Distribuição da produção de soja, em classes de produtores e de produção. Censo Agropecuário 1995/96.

\begin{tabular}{lcccc}
\hline $\begin{array}{c}\text { Classes de } \\
\text { produtores }\end{array}$ & $\begin{array}{c}\text { Classes de } \\
\text { produção (ton) }\end{array}$ & $\begin{array}{c}\text { Informantes } \\
\text { Número }\end{array}$ & $\%$ & $\begin{array}{c}\text { Produção } \\
\%\end{array}$ \\
\hline Mini & {$[0,10]$} & 104.061 & 42,82 & 1,82 \\
Pequenos & $(10,20]$ & 37.217 & 15,32 & 2,51 \\
& $(20,50]$ & 45.682 & 18,80 & 6,82 \\
Médios & $(50,100]$ & 22.885 & 9,42 & 7,48 \\
Grandes & $(100,200]$ & 14.344 & 5,90 & 9,33 \\
Total & Mais de 200 & 18.810 & 7,74 & 72,04 \\
\hline
\end{tabular}

Fonte IBGE, solicitação da Embrapa. Produção informada $=21.590 .685$ ton. Gini=0,83 


\section{Leite}

A tabela informa a produção obtida por 1,8 milhão de informantes, que produziram 17,9 bilhões de litros, e não apenas a comercializada. Os mini e pequenos produtores dominaram o abastecimento; em número, corresponderam a $98,1 \%$ do universo de informantes e, em produção, responderam por $72,0 \%$ do abastecimento, do ponto de vista da oferta nacional.

Os médios e grandes produtores corresponderam a 1,9\% do universo de informantes e a uma produção de 28,0\%. Assim, o leite está muito próximo do feijão, primeira safra, e distante do arroz, para não falar da soja, e a pequena e média produção abrigaram a grande maioria dos produtores e da produção.

Tabela 6 - Distribuição da produção de leite, em classes de produtores e de produção. Censo Agropecuário 1995/96

\begin{tabular}{lcccc}
\hline $\begin{array}{c}\text { Classes de } \\
\text { produtores }\end{array}$ & $\begin{array}{c}\text { Classes de } \\
\text { produção (ton) }\end{array}$ & $\begin{array}{c}\text { Informantes } \\
\text { Número }\end{array}$ & $\%$ & $\begin{array}{c}\text { Produção } \\
\%\end{array}$ \\
\hline Mini & {$[0,50]$} & 1.586 .667 & 87,66 & 36,09 \\
Pequenos & $(50,100]$ & 126.458 & 6,99 & 18,15 \\
& $(100,200]$ & 63.072 & 3,48 & 17,78 \\
Médios & $(200,400]$ & 24.041 & 1,33 & 13,24 \\
Grandes & $(400,800]$ & 7.338 & 0,41 & 7,94 \\
Total & Mais de 800 & 2.465 & 0,13 & 6,80 \\
\hline
\end{tabular}

Fonte: IBGE, solicitação da Embrapa. Produção anual informada = 17.931.249.210 litros. Gini $=0,55$.

\subsection{Retornos à escala}

A função de produção foi estimada com base nos dados coletados pela Fundação Getúlio Vargas, em 1997 e 1998. Usou-se uma subamostra de 
agricultores de 100 ou menos hectares, a qual cobriu 1812 estabelecimentos e a subamostra 963. Calculou-se a renda líquida e foram encontrados 252 estabelecimentos de renda líquida não-negativa e 711 de renda líquida negativa. A função de produção, embora estimada para os dois grupos, em conjunto, permite separá-los para a análise. Detalhes adicionais estão em Alves Sousa e Brandão, 2001.

Os indicadores de renda e de eficiência são muito piores para o grupo de renda líquida negativa. Um dos motivos é que esse grupo operava com uma função de produção de retornos crescentes, razão por que não puderam expandir a produção até que os retornos decrescentes mostrassem a face. Já o outro grupo atingiu a fase de retornos decrescentes, embora não estivesse otimizando o uso dos recursos.

Segundo esses autores, a função de produção dos agricultores que tiveram renda líquida negativa -711 produtores, apresentou retorno crescente à escala, o que indica que os produtores estão longe de explorar sua capacidade de gestão. Se duplicassem todos os insumos, obteriam mais do dobro de renda líquida, mas novamente encontrariam o crédito de custeio e também o de investimento como pedras de tropeço. Remover essas restrições é crucial para o programa de agricultura familiar e de reforma agrária. Este grupo de agricultores, a grande maioria deles, remunerava a mão-de-obra familiar mais do que a produtividade marginal permite. A saída é expandir a produção, depois de reorganizá-la, também é importante expandir as oportunidades de emprego fora da fazenda. Neste caso, é muito oportuno o serviço de transporte, meio rural cidade, que as prefeituras começam a oferecer, o qual não deve beneficiar somente as crianças em idade escolar.

A função de produção do grupo de produtores de renda líquida nãonegativa apresentou retornos decrescentes à escala. Considerando-se, isoladamente, terra, capital e trabalho, a maioria dos estabelecimentos está subtilizando esses fatores. Embora tenha o grupo expandido a produção até o ramo de retornos decrescentes, estão aquém do nível ótimo dos insumos. Por que não se usa mais insumo? A maior restrição é de 
crédito. Os recursos próprios, embora sejam a maior fonte de financiamento, são insuficientes.

\section{Conclusões}

O trabalho examinou a questão da escala de produção. A hipótese básica é que a função de produção tem três ramos - de retornos crescentes, constantes e decrescentes, o que corresponde a uma função custo na forma de um U. Empiricamente, pode-se encontrar uma função de produção coerente com retornos crescentes. Deu-se um exemplo, ao lado de outro de retorno decrescente. Mas a firma opera no ramo de retorno crescente ou constante, porque enfrenta restrições que não permitem a expansão da produção, por isto, o nível de produção não está otimizado, e o equilíbrio é instável.

Os retornos constantes e crescentes são incompatíveis com mercados competitivos e há evidências de que o tamanho do estabelecimento, medido pela área, está crescendo no Brasil, embora isto não favoreça a hipótese de retornos crescentes o constantes. À medida que se diminuem as imperfeições de mercado, o que ocorre no Brasil, a área cresce. A inflação do período 1950-90 transformou a terra em reserva de valor, motivando a aquisição de terra, o que foi facilitado pelo crédito subsidiado. $\mathrm{O}$ desenvolvimento tecnológico e as indivisibilidades, num ambiente de êxodo rural acelerado, contribuíram para a expansão da área dos estabelecimentos e do volume de negócios destes. Assim, os resultados econométricos que evidenciam retornos constantes ou crescentes podem estar contaminados pela influência desses fatores.

Quando o volume de produção se correlaciona positivamente com índices de eficiência, é importante examinar as restrições que impedem que a correlação seja nula. Não existe razão teórica para correlação positiva ou negativa, quando prevalecem mercados competitivos. 
Examinou-se a distribuição do volume de produção para o arroz, as três safras de feijão, milho, soja, café e leite. Classificou-se o volume de produção em mini, pequeno, médio e grande. Nas classes mini e pequeno concentrou grande parte dos produtores que contribuíram muito pouco para o abastecimento e exportações, exceto para o feijão primeira safra e leite. Nas demais explorações, a grande e a média produção tiveram maior impacto. Embora os dados não permitam, cultura-a-cultura, discernir a evolução, percebe-se que, nas culturas já modernas, a pequena produção, embora importante porque diz respeito a um grande número de agricultores, pouco representa para o abastecimento. Em razão do custo crescente de oportunidade do tempo da mão-de-obra familiar e do trabalho em geral, prevê-se que a média e a grande produção possam explicar grande parte da oferta, como da soja e do arroz, enquanto a pequena deverá perder relevância, entre outras razões, porque as famílias serão mais exigentes em padrão de vida.

Os dados alertam para a renda pequena, que é gerada pela maioria de nossos produtores, e que deve haver fortes restrições no caminho que precisam percorrer para otimizarem o nível de produção. Os assentados da reforma agrária e a agricultura familiar ficarão à margem do progresso, se essas restrições não forem removidas. Como os médios e grandes produtores têm condições de ultrapassar as restrições, o dualismo de nossa agricultura, milhões de pobres, de um lado, e milhares de bem sucedidos, do outro, aprofundará, se não forem dadas oportunidades iguais a todos.

\section{Referências Bibliográficas}

ALVES, Eliseu A Função Custo, Brasília, EMBRAPA, 1996 (monografia sobre a teoria da função custo).

ALVES, Eliseu, Souza, Geraldo da Silva, Brandão, Antônio Salazar P. A situação do produtor com menos de cem hectares, Revista de Política Agrícola, ano X, Jan/Fev/Mar 2001 27-36. 


\title{
CHAMBERS, Robert G. Applied production analysis: a dual approach, New York, Cambridge University Press, 1994.
}

\begin{abstract}
The paper develops the concept of return to scale at an elementary level, but rigorously. It is argued that constant and increasing returns are incompatible with competitive markets, because they imply the convergence to few firms, and this is not the case for the real world. The main point is that average cost curve has the shape of a $\mathrm{U}$, and, without restrictions, the firms converge to the branch of decreasing returns. If on the real world is detected increasing or constant returns, it suggests that it should be looked for the market imperfection that are the base of them. And results of increasing or constant returns of econometric models must be taken as a sign of market imperfections. Yet the knowledge of the market imperfections is crucial to design economic policies for economic development with equal opportunities for all. The pattern of six crops showed that the supply is largely in the hands of few farmers, and the great majority of them contribute with a small share of the production. This pattern is clearer for modern crops, as it is the case of soybeans. The results of an econometric model for two groups of small farmers-one with nonnegative profit and the other with negative profit, pointed out increasing returns for the poorer group, and that it was not able to expand production to the cost curve branch of decreasing returns in consequence of market failures.
\end{abstract}

Keywords: Return to scale, market struture, crops. 